\title{
Review
}

\section{Migration, fate and in vivo imaging of adult stem cells in the CNS}

\author{
E Sykováa, ${ }^{*, 2,3}$ and $\mathrm{P}$ Jendelová ${ }^{1,2,3}$
}

\begin{abstract}
Adult stem cells have been intensively studied for their potential use in cell therapies for neurodegenerative diseases, ischemia and traumatic injuries. One of the most promising cell sources for autologous cell transplantation is bone marrow, containing a heterogenous cell population that can be roughly divided into hematopoietic stem and progenitor cells and mesenchymal stem cells (MSCs). MSCs are multipotent progenitor cells that, in the case of severe tissue ischemia or damage, can be attracted to the lesion site, where they can secrete bioactive molecules, either naturally or through genetic engineering. They can also serve as vehicles for delivering therapeutic agents. Mobilized from the marrow, sorted or expanded in culture, MSCs can be delivered to the damaged site by direct or systemic application. In addition, MSCs can be labeled with superparamagnetic nanoparticles that allow in vivo cell imaging. Magnetic resonance imaging (MRI) is thus a suitable method for in vivo cell tracking of transplanted cells in the host organism. This review will focus on cell labeling for MRI and the use of MSCs in experimental and clinical studies for the treatment of brain and spinal cord injuries.
\end{abstract}

Cell Death and Differentiation (2007) 14, 1336-1342; doi:10.1038/sj.cdd.4402140; published online 30 March 2007

Stem and progenitor cells from various sources are currently studied for their broad potential use in the treatment of numerous neurodegenerative diseases, brain ischemia and spinal cord injury $(\mathrm{SCl})$. It has been observed in many animal models ${ }^{1-3}$ that their transplantation induces functional improvement. Cells, based on their origin during development or their location in the body, can be classified as embryonic stem cells, fetal multipotent stem cells or adult stem and progenitor cells. Based on their unlimited differentiation potential, the most promising are embryonic stem cells derived from the inner cell mass of the blastocyst. However, using these cells in human medicine is still a distant goal because their proliferation and differentiation cannot be controlled and the risk of tumor formation or differentiation into an improper phenotype is still considerable. Fetal stem cells, although they are organ-specific committed cells, are very limited in quantity and cannot be used in autologous transplantations. Adult stem cells can be found in the already developed tissues of the adult organism, including the brain, ${ }^{4,5}$ fat $^{,}{ }^{6-8}$ skin, ${ }^{9,10}$ kidney, ${ }^{11,12}$ peripheral blood ${ }^{13,14}$ and bone marrow. ${ }^{15-17}$ Their main advantage is their potential use in autologous transplantation without the need for immunosuppressive treatment. In addition, stem cells from fat, skin, blood and bone marrow can be relatively easily isolated and expanded in vitro.

\begin{abstract}
Mesenchymal Stem Cells
Bone marrow can serve as a source of different cell populations that can be roughly divided into hematopoietic stem and progenitor cells and mesenchymal stem cells (MSCs). These are multipotent adult progenitor cells that are capable of differentiating into bone, ${ }^{18}$ cartilage, ${ }^{19}$ muscle ${ }^{20}$ tendon and ligament, ${ }^{21}$ and fat cell phenotypes. The demonstrated ability of MSCs to differentiate into different phenotypes makes MSCs excellent candidates as therapeutic cells for the repair of damaged tissue. Several laboratories have studied MSCs in tissue repair models. The results from these experiments have been mixed: often, MSCs have been shown to express differentiated markers in very low numbers accompanied by a measurable therapeutic effect, or a therapeutic effect is present but no differentiation is detected. In the case of severe tissue ischemia or damage, MSCs can be attracted to the damaged site, where they secrete bioactive factors that trophically influence the repair and regenerative process. MSCs can be mobilized from the marrow or can be expanded in culture and delivered to the damaged site by direct or systemic injection. ${ }^{22}$ Once at the site of injury, MSCs produce factors that inhibit scarring and apoptosis, promote angiogenesis and stimulate host progenitors to divide and differentiate in order to repair the injured tissue. In this regard, the trophic effects of MSCs may have important clinical use.
\end{abstract}

\footnotetext{
${ }^{1}$ Department of Neuroscience, Institute of Experimental Medicine ASCR, Prague, Czech Republic; ${ }^{2}$ Center for Cell Therapy and Tissue Repair, Charles University, Second Medical Faculty, Prague, Czech Republic and ${ }^{3}$ Department of Neuroscience, Charles University, Second Medical Faculty, Prague, Czech Republic *Corresponding author: E Syková, Institute of Experimental Medicine ASCR, Vídeňská 1083, 14220 Prague 4, Czech Republic. Tel: + 420 24106 2230; Fax: + 42024106 2783; E-mail: sykova@biomed.cas.cz

Keywords: contrast agents; mesenchymal stem cells; nanoparticles; photochemical lesion; spinal cord injury; stroke

Abbreviations: MSCs, mesenchymal stem cells; MRI, magnetic resonance imaging; SPIO, superparamagnetic iron oxide; PCR, polymerase chain reaction; PC-SPIO, polycation-bound superparamagnetic iron oxide; SCl, spinal cord injury; BMCs, bone marrow cells; G-CSF, granulocyte colony-stimulating factor; AT, autoimmune T cells; NSCs, neural stem cells

Received 31.1.07; revised 07.3.07; accepted 09.3.07; Edited by P Nicotera; published online 30.3.07
} 


\section{Cellular Imaging}

Non-invasive cellular imaging allows the real-time tracking of grafted cells as well as the monitoring of their migration. Several techniques for in vivo cellular imaging are now available that allow the characterization of transplanted cells in the living organism, including magnetic resonance imaging (MRI), ${ }^{23}$ bioluminescence, ${ }^{24}$ positron emission tomography ${ }^{25}$ and multiple photon microscopy. ${ }^{26}$ All of these imaging methods, based on different principles, provide distinctive, usually complementary information. In this review, we will focus on cell labelling for $\mathrm{MRI}$, as $\mathrm{MRI}$ is non-invasive, clinically translatable and displays good resolution, ranging from $50 \mu \mathrm{m}$ in animals up to $300 \mu \mathrm{m}$ in whole body clinical scanners. In addition to information about grafted cells, MRI can provide information about the surrounding tissue (i.e., lesion size, edema or inflammation), which may have an effect on graft survival or the functional recovery of the tissue. ${ }^{27-30}$

\section{Cell Labeling}

For cellular MRI, cells need to be labeled with MR contrast agents in order to visualize them in the host tissue. MR contrast agents contain metal ions, which define their relaxation properties. Paramagnetic metals such as gadolinium, iron and manganese mainly affect $\mathrm{T} 1$ relaxation, whereas superparamagnetic iron oxide (SPIO) nanoparticles predominantly reduce $\mathrm{T} 2$ and $\mathrm{T}_{2}{ }^{*}{ }^{31}$ Particularly, $\mathrm{T}^{*}$ is reduced due to the induction of strong field inhomogeneities.

For cell labeling, contrast agents can be either bound to the external surface of the cell membrane or internalized into the cytoplasm. Immunomagnetic labels that are used for magnetic cell sorting, that is, microbeads, may serve as a contrast agent linked to an antibody that is bound to the respective cell. The immunomagnetic label has a superparamagnetic core, the size of which is comparable to the metal compound of an MR contrast agent. Particles that do not internalize do not affect cell viability, and keeping cells in culture is not required for cell labeling; however, their attachment to the outer cell membrane is likely to interfere with cell-surface interactions, and they may easily detach from the membrane or be transferred to other cells. Commercially available cell isolation kits for the magnetic separation of CD34 ${ }^{+}$cells were tested. ${ }^{32}$ The average iron content per cell, determined by spectrometry, was $0.275 \mathrm{pg}$. This value was lower by two orders of magnitude than in the case of cell labeling using intracellular labels; nevertheless, it still provided sufficient MR contrast. The cells were grafted into rats with a cortical photochemical lesion and were detected as a hypointense spot on T2weighted images $24 \mathrm{~h}$ after grafting. ${ }^{32}$ The presence of cells in the lesion was confirmed by staining for human nuclei and by polymerase chain reaction (PCR).

Intracellular magnetic labels have their surface modified to facilitate their uptake by cells. Several modifications of iron oxide particles have now been described that induce an efficient internalization of the contrast agent while trying to minimize any deleterious effects on cellular functions. Surface coating (e.g., by dextran or polymers) ensures iron oxide nanoparticle stabilization and solubility in order to prevent aggregation. A suitable contrast agent for labeling rat or human MSCs, embryonic stem cells and olfactory ensheathing cells is a commercially available contrast agent based on dextran-coated SPIO nanoparticles, Endorem ${ }^{\mathbb{R}}$ (Guerbet, France). ${ }^{22,33,34}$ Endorem can be easily incorporated by endocytosis, and its uptake does not need to be facilitated by a transfection agent, which can damage large numbers of cells. ${ }^{35}$ On the day that nanoparticles were withdrawn, the efficiency of both rat or human MSC labeling (i.e., how many cells out of the total number of analyzed cells were labeled) was $50-70 \%$. Another labeling approach is based on combining a commercially available dextran-coated SPIO, such as Feridex ${ }^{\circledR 36}$ or Sinerem ${ }^{\circledR}, 37$ and a commercially available transfection agent, for example, Superfect ${ }^{\mathrm{TM}}$ polyL-lysine, Lipofectamin or Fugene ${ }^{\mathrm{TM}} \cdot{ }^{35,38}$ Transfection agents effectively transport nanoparticles into cells through electrostatic interactions. However, each combination of transfection agent and dextran-coated SPIO nanoparticle has to be carefully titrated and optimized for different cell cultures, as lower concentrations of transfection agent may result in insufficient cellular uptake, whereas higher concentrations may induce the precipitation of complexes or may be toxic to the cells. ${ }^{39}$ To overcome these drawbacks, polycation-bound superparamagnetic iron oxide (PC-SPIO) nanoparticles were developed. ${ }^{40}$ PC-SPIO nanoparticles combine the advantages of a low concentration of iron in the cell culture media $(15.4 \mu \mathrm{g} / \mathrm{ml})$ with facilitated uptake without the further use of any additives. ${ }^{41} \mathrm{~A}$ comparison of standard dextran-coated SPIO and PC-SPIO showed that labeling cells with PC-SPIO nanoparticles was more efficient than labeling with Endorem; that is, more cells out of the total number of analyzed cells were labeled with PC-SPIO nanoparticles than with Endorem (Figure 1a). The PC-SPIO nanoparticle suspension was used at a much lower iron concentration per milliliter of culture media $(15.4 \mu \mathrm{g} / \mathrm{ml})$, in comparison with Endorem, for which $112.4 \mu \mathrm{g} / \mathrm{ml}$ in the culture media was used, and the cells were incubated with both labels for 3 days. The average amount of iron present in rat MSCs was determined by spectrophotometry after mineralization of iron-labeled cell suspensions. In PC-SPIO-labeled cells, even though the concentration of iron in the culture media was 10 times lower $(15.4 \mu \mathrm{g} / \mathrm{ml}$ culture media), the average amount of iron was $38 \mathrm{pg} / \mathrm{cell}$, whereas in Endorem-labeled cells only $17 \mathrm{pg} / \mathrm{cell}$. MR images of phantoms containing suspensions of PC-SPIO-labeled cells showed a much stronger hypointense signal than did MR images of Endorem-labeled cells (Figure 1b-d). The MR detection limit in vitro was 0.4 cells in the image voxel, whereas in vivo it was 1000 cells injected in $2 \mu$ of PBS (Figure $1 \mathrm{e}$ and $\mathrm{f}$ ). Compared with Endorem, the better internalization of PC-SPIO particles into the cells enables the easier MRI detection and tracking of the cells in the tissue after transplantation. As another suitable surface modification to enhance nanoparticle transport into the cells, D-mannose was selected, as the cell surface is known to possess receptors for this molecule ${ }^{42}$ and thus the coated nanoparticles can be easily internalized. New surface-modified iron oxide nanoparticles were developed by the precipitation of $\mathrm{Fe}(\mathrm{II})$ and $\mathrm{Fe}$ (III) salts with ammonium hydroxide followed by the oxidation of the precipitated magnetite with sodium hypochlorite with the subsequent addition of D-mannose solution. ${ }^{43}$ The efficiency of rat MSC labeling was about $80 \%$, and cells 

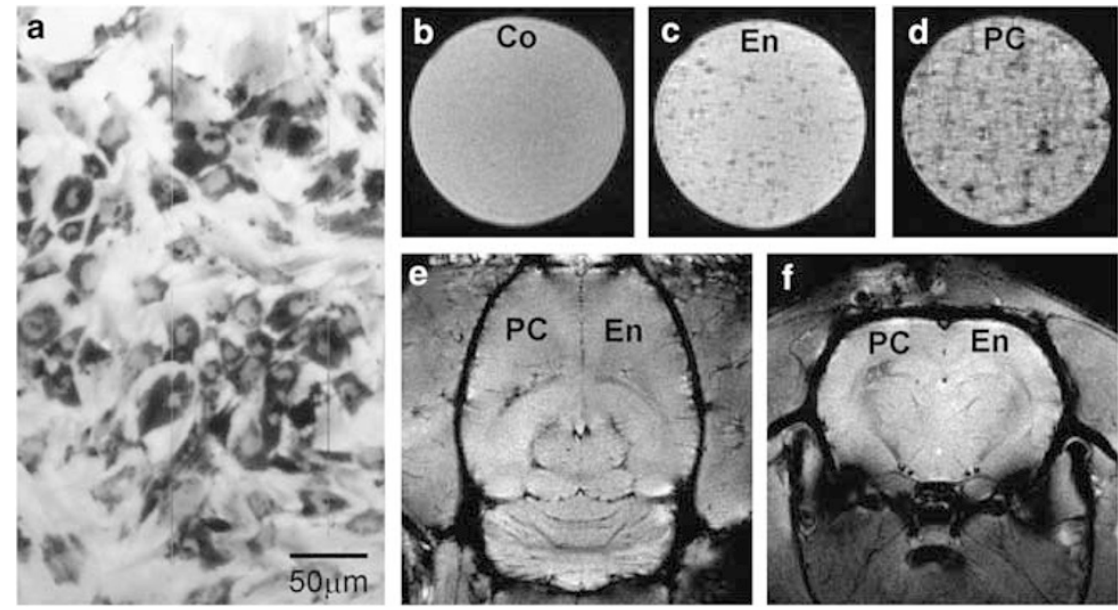

Figure 1 (a) PC-SPIO-labeled rat MSCs in culture stained with Prussian blue. (b-c) MR images of phantoms formed by a set of test tubes containing a suspension of rat MSCs in $0.5 \mathrm{ml}$ gelatin. The control (Co) cells were unlabeled (b) or labeled with Endorem (c) or with PC-SPIO nanoparticles (d). There were 10000 cells in the phantoms, corresponding to 0.4 cells per image voxel. (e) Axial and coronal (f) MR images of a rat brain with 1000 cells labeled with PC-SPIO nanoperticles implanted in the left hemisphere (PC) and 1000 Endorem-labeled cells implanted in the right hemisphere (En). MR images were taken 3 days after implantation. Modified from Sykova and Jendelova $^{61}$

labeled with D-mannose-coated nanoparticles possessed very high relaxivity $(12.1 / \mathrm{s} / \mathrm{million}$ of cells $/ \mathrm{ml})$ when compared to cells labeled with Endorem (1.24/s/million of cells $/ \mathrm{ml})$. The average amount of iron as determined by spectrophotometry after mineralization was $51.7 \mathrm{pg}$ of iron per cell. Therefore, D-mannose-modified iron oxide nanoparticles are another promising tool for labeling living cells for diagnostic and therapeutic applications in cell-based therapies. Other strategies for developing MR contrast agents that are easy to detect include the utilization of viral protein cages ${ }^{44}$ or the use of internalizing monoclonal antibodies. ${ }^{45}$ Cells in suspension can be labeled using magnetoelectroporation. ${ }^{46}$

\section{The Use of MSCs in the Treatment of CNS Disorders}

Preclinical studies. Recently, numerous studies have been published that describe the use of rat or human MSCs in the treatment of brain or spinal cord disorders. After transplantation into the brain, they respond to intrinsic signals and migrate toward the site of injury. In some studies, they differentiated in vivo into astrocytes and even neurons. ${ }^{47,48}$ Human MSCs were injected into rats after middle cerebral artery occlusion. ${ }^{49,50}$ In both studies, implanted cells reduced the lesion volume and elicited functional improvement compared with the control sham group. As MSCs can be easily genetically modified, numerous studies in which MSCs overexpress some bioactive molecules have appeared. ${ }^{50-52}$ Human MSCs expressing brain-derived neurotrophic factor or human MSCs producing placental growth factor have an enhanced effect on functional outcome and lesion volume compared to human MSCs alone, suggesting the use of human MSCs as vehicles for the delivery of growth factors. As MSC-based treatments for brain disorders have advanced rapidly, the visualization of implanted stem cells in experimental models of brain disorders is at the leading edge of potential applications of MRI. Endorem-labeled human MSCs, or
Endorem/BrdU-co-labeled rat MSCs, were grafted into rats (Wistar, males, 2-3 months old) with a cortical photochemical lesion. ${ }^{33,34}$ The cells were grafted either intracerebrally into the hemisphere contralateral to the lesion or intravenously into the femoral vein (Figure 2). Rats with grafted stem cells were examined weekly for a period of 3-7 weeks post transplantation using a 4.7T Bruker spectrometer. Single sagittal, coronal and transversal images were obtained by a fast gradient echo sequence for localizing subsequent T2-weighted transversal images measured by a standard turbospin echo sequence. The lesion was visible on T2-weighted images as a hyperintense signal (Figure 2a). One week after grafting, a hypointense signal was found in the lesion, which intensified during the second and third weeks regardless of the route of administration; its intensity corresponded to Prussian blue staining or anti-BrdU staining (Figure 2b-f, 3a). Human MSCs were demonstrated in the lesion by GFP labeling and by the PCR detection of human DNA (a human-specific $850 \mathrm{bp}$ fragment of $\alpha$-satellite DNA from human chromosome 17; Figure $3 b-d)$. Less than $3 \%$ of the MSCs that migrated into the lesion expressed the neuronal marker NeuN when tested 28 days post-implantation. ${ }^{33}$ No GFAP-positive cells were found in the lesion.

A different approach was adopted when tracking human MSCs in a rat model of chronic stroke. ${ }^{53}$ A standard contrast agent, gadolinium diethylenetriamine pentaacetic acid (GdDTPA), was transfected using the cellular labeling substance, Effectene, in immortalized human MSCs. The Gd-DTPAlabeled cells migrated and homed into the penumbric area. Using double immunofluorescence, the transplanted cells were seen to differentiate into glial cells, neurons and vascular endothelial cells.

For their trophic and potential neuroprotective effects, MSCs are widely used in the treatment of SCI. Rat MSCs have been reported to bridge the epicenter of an $\mathrm{SCl}^{54}$ Evaluating the effect of different bone marrow cell (BMC) populations on morphological and functional recovery after 

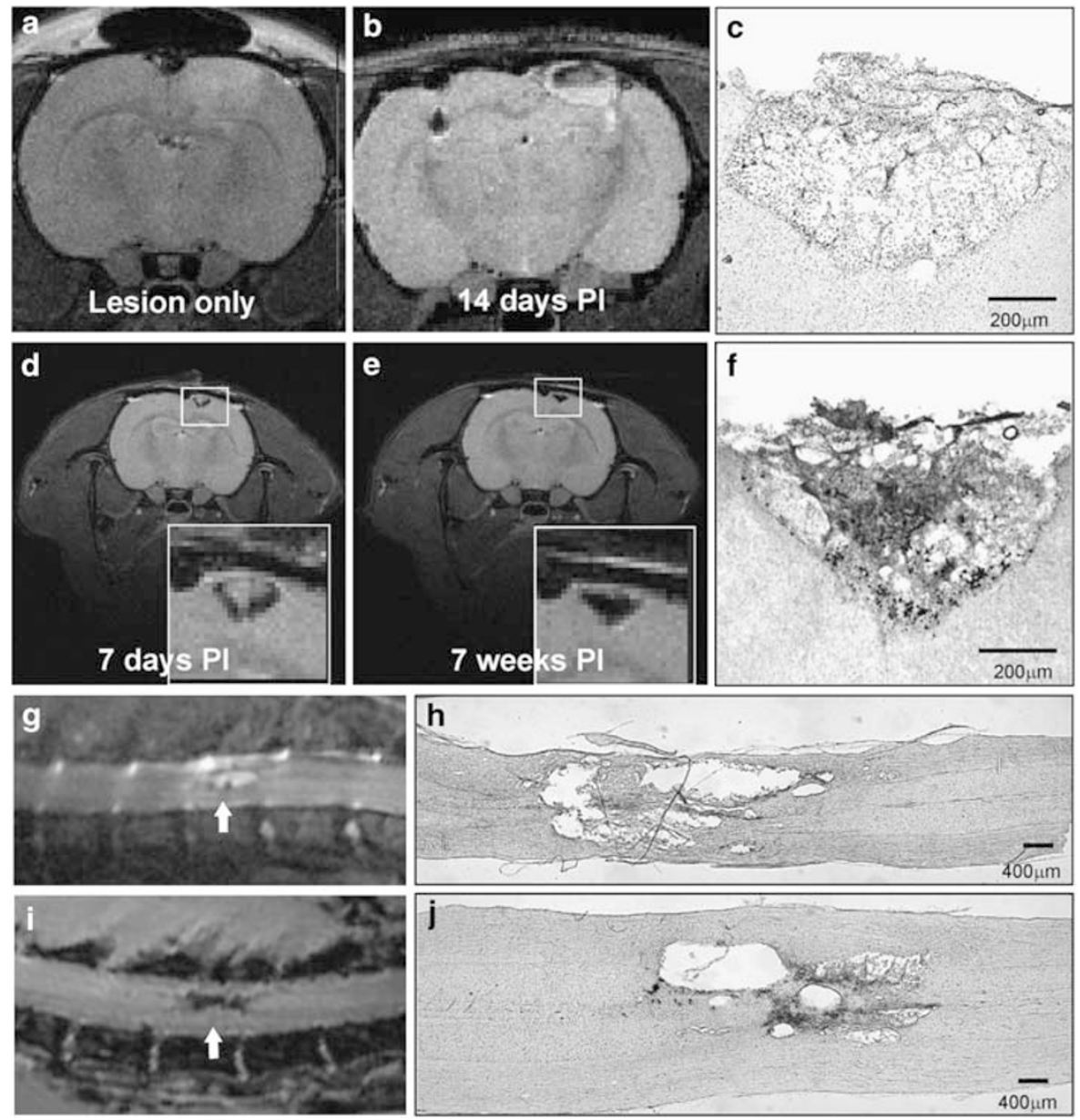

Figure 2 (a) Cortical photochemical lesion visible on MR images 2 weeks after induction as a hyperintensive area. (b) Both the cell implant (MSCs in the hemisphere contralateral to the lesion) and the lesion are hypointense in MR images 2 weeks after implantation. (c) A few cells weakly stained for Prussian blue were found in the photochemical lesion in animals without implanted cells. ( $\mathbf{d}$ and $\mathbf{e}$ ) A hypointense signal in the lesion was seen 7 days after the i.v. injection of Endorem-labeled rat MSCs (d) and persisted for 7 weeks (e). Insets show a higher magnification view of the lesion. (f) Massive invasion of rat MSCs (Prussian blue staining counterstained with hematoxylin) into a photochemical lesion 7 weeks after i.v. injection. (g) Longitudinal section of a spinal cord compression lesion on MR images, 5 weeks after compression. The lesion is seen as a hyperintensive area (arrow). (i) Longitudinal image of a spinal cord compression lesion populated with intravenously injected nanoparticle-labeled MSCs, 4 weeks after implantation. The lesion with nanoparticle-labeled cells is visible as a dark hypointensive area (arrow). (h) Prussian blue staining of a spinal cord compression lesion (control animal). (j) Prussian blue staining of a spinal cord lesion with intravenously injected nanoparticle-labeled MSCs. The lesion is populated with Prussian blue-positive cells. Modified from Sykova and Jendelova ${ }^{55}$

$\mathrm{SCl}$ is an important aspect of preclinical research. In rats with a balloon-induced spinal cord compression lesion, an improvement of locomotor and sensory function was found following an intravenous (i.v.) injection of Endorem-labeled non-hematopoietic rat MSCs. ${ }^{55,56}$ The results obtained were compared with those following the implantation of a freshly isolated mononuclear fraction of bone marrow containing stromal cells, hematopoietic and non-hematopoietic stem and precursor cells and lymphocytes (BMCs), and with those following the injection of granulocyte colony-stimulating factor (G-CSF). G-CSF is a growth factor that mobilizes endogenous BMCs containing mainly hematopoietic stem cells, but also progenitor cells and lymphocytes. ${ }^{22}$

Rat MSCs labeled with Endorem were injected intravenously into the femoral vein 1 week after lesioning. ${ }^{22} \mathrm{MR}$ images were taken ex vivo 4 weeks after implantation using a standard whole body resonator. Functional status was assessed weekly for 5 weeks after spinal cord lesioning, using the Basso-Beattie-Bresnahan (BBB) locomotor rating score and the plantar test. Lesioned animals with grafted MSCs, BMCs or treated with G-CSF had higher locomotor scores as indicated by their BBB scores and showed better responses in sensitivity testing using the plantar test than did control animals. However, the functional improvement was more pronounced in MSC-treated rats. On MR images, the lesion was observed as an inhomogeneity in the tissue texture with a hyperintense signal only in the area of the SCI (Figure $2 \mathrm{~g}$ and $\mathrm{i}$. Images of longitudinal spinal cord sections from animals grafted with nanoparticle-labeled MSCs showed the lesion as a dark hypointense area. Prussian blue staining confirmed a large number of positive cells present in the lesion site (Figure $2 \mathrm{~h}$ and j). Colocalization of ED1 staining (microglia/macrophages) and Prussian blue staining excluded the possibility that free nanoparticles were taken up by 

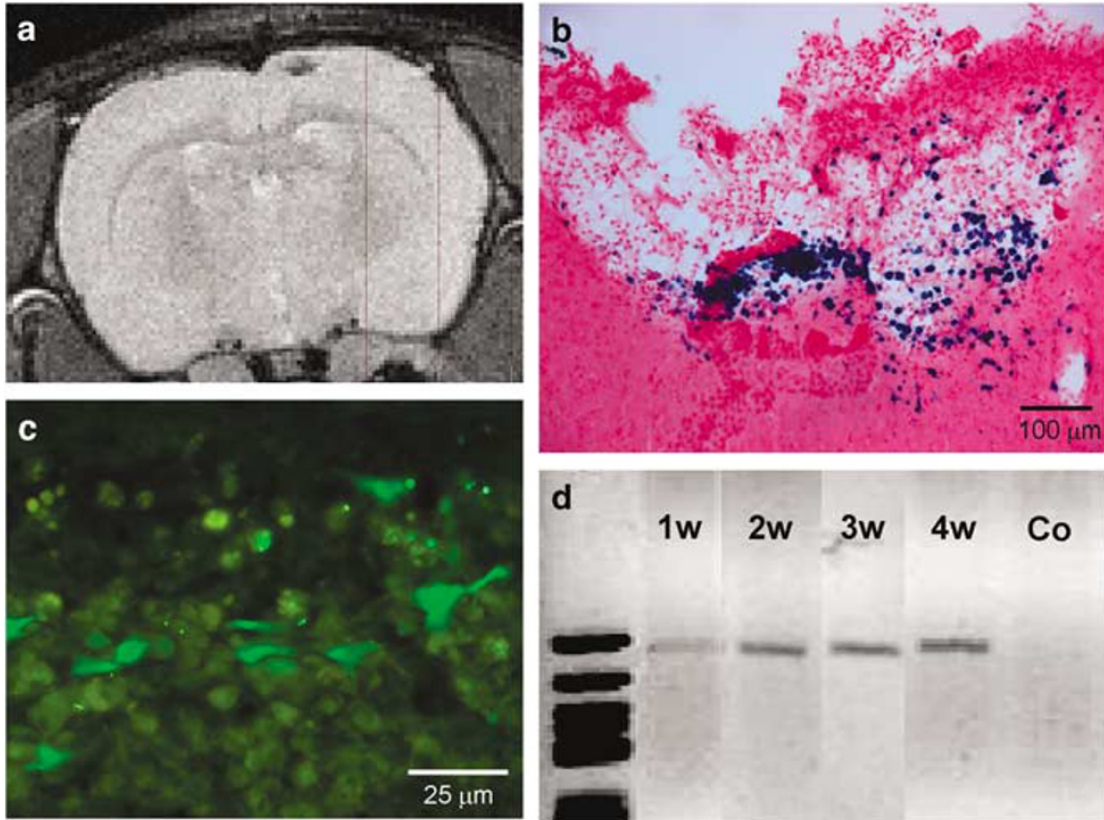

Figure 3 (a) A hypointensive signal in a lesion 4 weeks after the i.v. grafting of human MSCs labeled with Endorem. (b) Prussian blue-positive cells in a cortical photochemical lesion. (c) GFP-human MSCs in a lesion 2 weeks after i.v. injection. (d) PCR detection of a human-specific 850 bp fragment of $\alpha$-satelite DNA from human chromosome 17 in brain sections with a photochemical lesion, 1-4 weeks after grafting (1w-4w, Co - animal injected with PBS)

macrophages, as Prussian blue staining did not, for the most part, colocalize with ED1 staining. Morphometric measurements in the center of the lesions showed an increase in white matter volume in cell-treated animals. The spared crosssectional area of the gray matter was also significantly larger in MSC-treated animals.

Transplantation of MSCs in rodent models has proved to be an effective therapeutic approach for SCl. Additionally, MSCs isolated from rhesus monkey bone marrow were induced ex vivo to differentiate into neural lineage cells, then injected into rhesus monkeys with SCl. Monkeys achieved Tarlov grades 2 and 3 and nearly normal sensory responses 3 months after cell transplantation. Cortical somatosensory-evoked potentials as well as motor-evoked potentials showed recovery features. About $10 \%$ of the implanted cells expressed some neural marker.

Clinical studies. Clinical studies are necessary for transferring preclinical findings from animal experiments to humans. The therapeutic window, the implantation strategy, the best method of administration, the number of cells and the possible side effects must finally be tested in human clinical trials. Recently, several case reports and clinical studies (Phase I/II) have been published. These studies mainly used autologous MSCs or BMCs. Based on recent experimental studies, autologous BMC implantation was used in our Phase I/II clinical trial in patients $(n=20)$ with a transversal spinal cord lesion at Motol Hospital in Prague, Czech Republic. ${ }^{57}$ The patients received transplants 10-467 days post-injury. The follow-up examination was performed at 3,6 and 12 months after implantation using standard neurological classification of $\mathrm{SCl}$, including the ASIA protocol, the Frankel score, the recording of motor and somatosensory-evoked potentials, and MRI evaluation of lesion size. The study compared intra-arterial (via catheterization of vertebral artery) versus i.v. administration of all mononuclear cells in groups of acute (10-30 days post$\mathrm{SCI}, n=7)$ and chronic patients (2-17 months post-injury, $n=13)$. Improvement in motor and/or sensory functions was observed within 3 months in five of six patients with intraarterial administration, in five of seven acute, and in one of 13 chronic patients (Figure 4). There have been no complications during patient follow-up for 2-3 years after implantation. A recent clinical study was performed by Park et al. ${ }^{58}$ on six patients with $\mathrm{SCl}$. A combination of autologous BMCs implanted as early as 7 days after $\mathrm{SCl}$ and subsequent repetitive mobilization of BMCs with granulocyte macrophage-colony-stimulating factor (GM-CSF) resulted in five out of six patients showing improved motor and/or sensory function. Both clinical studies showed that the implantation of autologous BMCs is safe, suggesting that the observed effects could be due to cell therapy. Also, the outcome in one chronic patient, who was in stable condition for several months before cell implantation, is promising. ${ }^{57}$

Among other studies that have been performed, we would like to highlight a case report from Argentina on the electrophysiological and functional recovery of two patients with chronic $\mathrm{SCl}^{59} \mathrm{MSC}$ were cocultured with the patients' autoimmune T (AT) cells to be transdifferentiated into neural stem cells (NSCs). Forty-eight hours before NSC implant, the patients received an i.v. infusion of $5 \times 10^{8}-1 \times 10^{9}$ AT cells. NSCs were infused via an artery feeding the lesion site. Patient 1 was a 19-year-old man with a SCl who presented with paraplegia and a sensitivity level corresponding to his sixth thoracic segment (T6). He received two AT-NSC 
Intraarterial BMCs
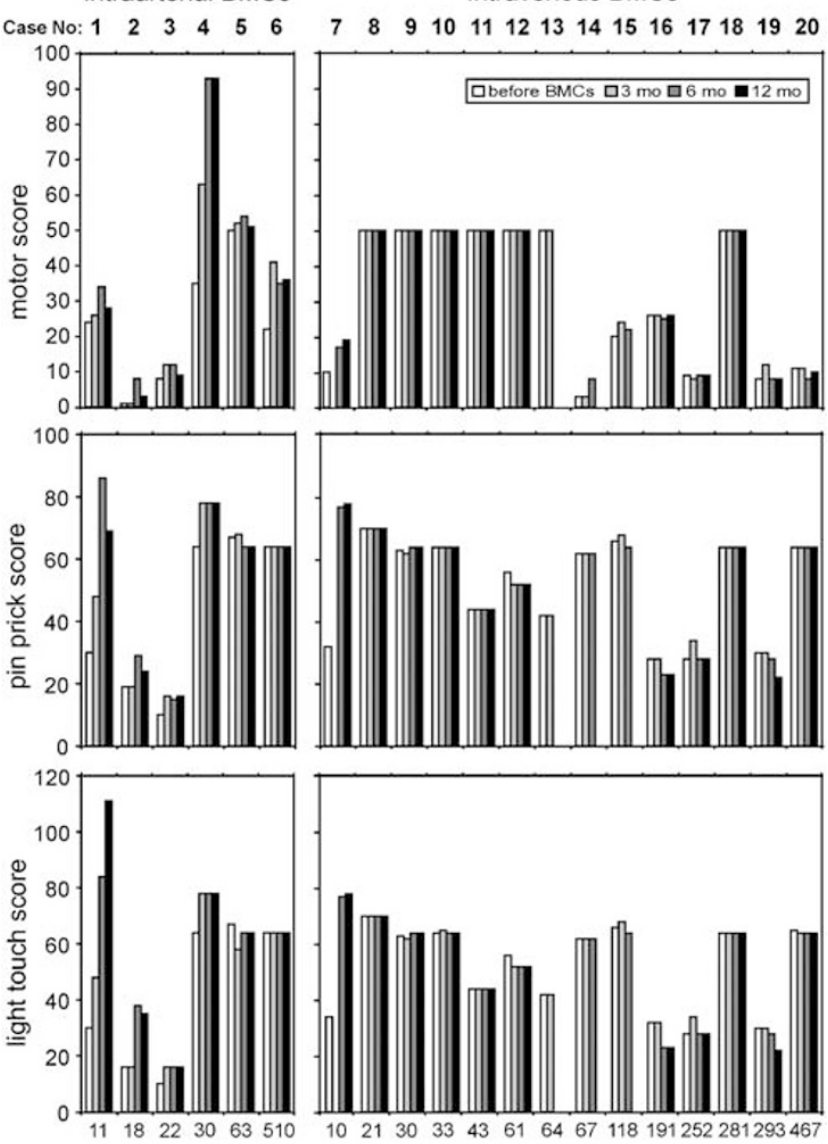

Days after BMC implantation

Figure 4 Motor and sensory scores of 20 patients before and 3, 6 and 12 months after BMC implantation. Motor score was improved in all acute patients and one chronic patient who received BMCs via vertebral artery (cases 1, 2, 3, 4 and 6). Motor score was also improved in one acute patient who received BMCs intravenously (case 7). Sensory functions (pin prick score, light touch score) were markedly improved in one patient with intra-arterial (case 1) and one with i.v. (case 4) BMC implantation. Adopted from Sykova et al. ${ }^{57}$

treatments and neurorehabilitation for 6 months. At present, his motor level corresponds to his first sacral segment (S1) and his sensitive level to the fourth sacral segment (S4). Patient 2 was a 21-year-old woman who had a lesion that extended from her third to her fifth cervical vertebrae (C3-C5). Before her first therapeutic cycle, she had severe quadriplegia and her sensitive level corresponded to her second cervical segment (C2). After 3 months of treatment, her motor and sensitive levels reached her first and second thoracic segments (T1-T2). No adverse events were detected in either patient. Intraspinal autologous MSC application was used in seven amyotrophic lateral sclerosis patients in Italy. ${ }^{60}$ No patient manifested major adverse events such as respiratory failure or death. Minor adverse events were intercostal pain irradiation and leg sensory dysesthesia, both reversible after a mean period of 6 weeks. No modification of the spinal cord volume or other signs of abnormal cell proliferation were observed. A significant slowing down of the linear decline of the forced vital capacity was evident in four patients 36 months after MSC transplantation.

\section{Conclusions and Further Perspectives}

Preclinical and clinical studies have not shown any deaths or significant health complications in experimental animals or patients given MSCs, demonstrating that this approach is safe for future use. For clinical studies, it is obvious that traditional histopathological methods for cell detection are not sufficient to inform us about the migration and fate of the grafted cells in the host tissue. Because of its high spatial resolution, MR imaging is suitable for monitoring the distribution of magnetically labeled cells. The technique of using MR to track magnetically labeled cells gives us information about the migration speed of the transplanted cells toward a brain or spinal cord lesion and about the cells' fate in CNS tissue. With proper attention to the limitations described above, labeling cells with superparamagnetic agents would enable us to follow the migration of such cells when transplanted into humans, establish the optimal number of transplanted cells, define therapeutic windows and monitor cell growth and possible side effects (malignancies).

In the case of large lesions, MSC transplantation can be combined with biocompatible artificial scaffolds that will bridge the cavities. By their rescue function, MSCs can assist the repair and regeneration of even large tissue defects.

Acknowledgements. This work was supported by grants from the Academy of Sciences of the Czech Republic AV0Z50390703, KAN201110651, the Ministry of Education, Youth and Sports of the Czech Republic 1M0021620803, LC554, the National Grant Agency of the Czech Republic GACR 309/06/1594, the Grant Agency of the Ministry of Health NR8339-3, and the EC-FP6 projects DiMl: LSHB-CT-2005-512146 and RESCUE: LSHB-CT-2005-518233.

1. Haas S, Weidner N, Winkler J. Adult stem cell therapy in stroke. Curr Opin Neurol 2005; 18: $59-64$

2. Dezawa M, Hoshino M, Nabeshima $Y$, Ide C. Marrow stromal cells: implications in health and disease in the nervous system. Curr Mol Med 2005; 5: 723-732.

3. Levy YS, Stroomza M, Melamed E, Offen D. Embryonic and adult stem cells as a source for cell therapy in Parkinson's disease. J Mol Neurosci 2004; 24: 353-386.

4. Taupin P. Adult neurogenesis in mammals. Curr Opin Mol Ther 2006; 8: 345-351.

5. Sohur US, Emsley JG, Mitchell BD, Macklis JD. Adult neurogenesis and cellular brain repair with neural progenitors, precursors and stem cells. Philos Trans $R$ Soc Lond B Biol Sci 2006; 361: 1477-1497.

6. Moseley TA, Zhu M, Hedrick MH. Adipose-derived stem and progenitor cells as fillers in plastic and reconstructive surgery. Plast Reconstr Surg 2006; 118 (Suppl 3): 121S-128S.

7. Nakagami H, Morishita R, Maeda K, Kikuchi Y, Ogihara T, Kaneda Y. Adipose tissuederived stromal cells as a novel option for regenerative cell therapy. J Atheroscler Thromb 2006; 13: 77-81.

8. Tholpady SS, Llull R, Ogle RC, Rubin JP, Futrell JW, Katz AJ. Adipose tissue: stem cells and beyond. Clin Plast Surg 2006; 33: 55-62, vi.

9. Teng L, Labosky PA. Neural crest stem cells. Adv Exp Med Biol 2006; 589: 206-212.

10. Watt FM, Lo Celso C, Silva-Vargas V. Epidermal stem cells: an update. Curr Opin Genet Dev 2006; 16: 518-524.

11. Morigi M, Benigni A, Remuzzi G, Imberti B. The regenerative potential of stem cells in acute renal failure. Cell Transplant 2006; 15 (Suppl 1): S111-S117.

12. Humphreys $\mathrm{BD}$, Duffield JD, Bonventre JV. Renal stem cells in recovery from acute kidney injury. Minerva Urol Nefrol 2006; 58: 13-21.

13. Elfenbein GJ. Granulocyte-colony stimulating factor primed bone marrow and granulocytecolony stimulating factor mobilized peripheral blood stem cells are equivalent for engraftment: which to choose? Pediatr Transplant 2005; 9 (Suppl 7): 37-47.

14. Fruehauf $\mathrm{S}$, Seeger $\mathrm{T}$, Topaly J. Innovative strategies for PBPC mobilization. Cytotherapy 2005; 7: 438-446.

15. Bobis S, Jarocha D, Majka M. Mesenchymal stem cells: characteristics and clinical applications. Folia Histochem Cytobiol 2006; 44: 215-230.

16. Koide Y, Morikawa S, Mabuchi Y, Muguruma Y, Hiratsu E, Hasegawa K et al. Two distinct stem cell lineages in murine bone marrow. Stem Cells 2007: 11.

17. Sottile V. Bone marrow as a source of stem cells and germ cells? Perspectives for transplantation. Cell Tissue Res 2007: 10. 
18. Haynesworth SE, Goshima J, Goldberg VM, Caplan Al. Characterization of cells with osteogenic potential from human marrow. Bone 1992; 13: 81-88.

19. Yoo JU, Barthel TS, Nishimura K, Solchaga L, Caplan Al, Goldberg VM et al. The chondrogenic potential of human bone-marrow-derived mesenchymal progenitor cells. J Bone Joint Surg Am 1998; 80: 1745-1757.

20. Wakitani S, Saito T, Caplan Al. Myogenic cells derived from rat bone marrow mesenchymal stem cells exposed to 5-azacytidine. Muscle Nerve 1995; 18: 1417-1426.

21. Young RG, Butler DL, Weber W, Caplan Al, Gordon SL, Fink DJ. Use of mesenchymal stem cells in a collagen matrix for Achilles tendon repair. J Orthop Res 1998; 16: 406-413.

22. Urdzikova L, Jendelova P, Glogarova K, Burian M, Hajek M, Sykova E. Transplantation of bone marrow stem cells as well as mobilization by granulocyte-colony stimulating factor promote recovery after spinal cord injury in rat. $J$ Neurotrauma 2006; 23: 1379-1391.

23. Modo M, Hoehn M, Bulte JW. Cellular MR imaging. Mol Imaging 2005; 4: 143-164.

24. Chaudhari AJ, Darvas F, Bading JR, Moats RA, Conti PS, Smith DJ et al. Hyperspectral and multispectral bioluminescence optical tomography for small animal imaging. Phys Med Biol 2005; 50: 5421-5441

25. Adonai N, Nguyen KN, Walsh J, lyer M, Toyokuni T, Phelps ME et al. Ex vivo cell labeling with 64Cu-pyruvaldehyde-bis(N4-methylthiosemicarbazone) for imaging cell trafficking in mice with positron-emission tomography. Proc Natl Acad Sci USA 2002; 99: 3030-3035

26. Mizrahi A, Lu J, Irving R, Feng G, Katz LC. In vivo imaging of juxtaglomerular neuron turnover in the mouse olfactory bulb. Proc Natl Acad Sci USA 2006; 103: 1912-1917.

27. Blanchet PJ, Konitsiotis S, Mochizuki H, Pluta R, Emerich DF, Chase TN et al. Complications of a trophic xenotransplant approach in Parkinsonian monkeys. Prog Neuropsychopharmacol Biol Psychiatry 2003; 27: 607-612.

28. Duan WM, Brundin $\mathrm{P}$, Widner $\mathrm{H}$. Addition of allogeneic spleen cells causes rejection of intrastriatal embryonic mesencephalic allografts in the rat. Neuroscience 1997; 77 599-609.

29. Philips MF, Muir JK, Saatman KE, Raghupathi R, Lee VM, Trojanowski JQ et al. Survival and integration of transplanted postmitotic human neurons following experimental brain injury in immunocompetent rats. J Neurosurg 1999; 90: 116-124.

30. Remy S, Canova C, Daguin-Nerriere V, Martin C, Melchior B, Neveu I et al. Different mechanisms mediate the rejection of porcine neurons and endothelial cells transplanted into the rat brain. Xenotransplantation 2001; 8: 136-148.

31. Wood ML, Hardy PA. Proton relaxation enhancement. J Magn Reson Imaging 1993; 3 149-156.

32. Jendelova $P$, Herynek V, Urdzíkova L, Glogarova K, Rahmatova S, Fales I et al. MR tracking of human CD34+ progenitor cells separated by means of immunomagnetic selection and transplanted into injured rat brain. Cell Transplantation 2005; 14: 173-182.

33. Jendelova P, Herynek V, De Croos J, Glogarova K, Andersson B, Hájek M et al. Imaging the fate of implanted bone marrow stromal cells labeled with superparamagnetic nanoparticles. Magn Reson Med 2003; 50: 767-776.

34. Jendelova P, Herynek V, Urdzikova L, Glogarova K, Kroupova J, Bryja V et al. MR tracking of transplanted bone marrow and embryonic stem cells labeled by iron oxide nanoparticles in rat brain and spinal cord. J Neurosci Res 2004; 76: 232-243.

35. Arbab AS, Yocum GT, Wilson LB, Parwana A, Jordan EK, Kalish $\mathrm{H}$ et al. Comparison of transfection agents in forming complexes with ferumoxides, cell labeling efficiency, and cellular viability. Mol Imaging 2004; 3: 24-32.

36. Frank JA, Miller BR, Arbab AS, Zywicke HA, Jordan EK, Lewis BK et al. Clinically applicable labeling of mammalian and stem cells by combining superparamagnetic iron oxides and transfection agents. Radiology 2003; 228: 480-487.

37. Hoehn M, Kustermann E, Blunk J, Wiedermann D, Trapp T, Focking M et al. Monitoring of implanted stem cell migration in vivo: a highly resolved in vivo magnetic resonance imaging investigation of experimental stroke in rat. Proc Natl Acad Sci USA 2002; 100: 1073-1078.

38. Arbab AS, Bashaw LA, Miller BR, Jordan EK, Lewis BK, Kalish $\mathrm{H}$ et al. Characterization of biophysical and metabolic properties of cells labeled with superparamagnetic iron oxide nanoparticles and transfection agent for cellular MR imaging. Radiology 2003; 229 838-846.

39. Kalish H, Arbab AS, Miller BR, Lewis BK, Zywicke HA, Bulte JW et al. Combination of transfection agents and magnetic resonance contrast agents for cellular imaging: relationship between relaxivities, electrostatic forces, and chemical composition. Magn Reson Med 2003; 50: 275-282.
40. Horak D, Sykova E, Babic M, Jendelova P, Hajek M (inventors) Superparamagnetic iron oxide nanoparticles with modified surface and their use as probes for stem cell labeling. Patent application no.: PV 1006-120, Czech Republic. 2006.

41. Glogarova K, Babic M, Herynek V, Horak D, Amemori T, Lesny P et al. Labeling efficiency and viability of stem cells cultured with dextran-coated and polycation-bound iron oxide nanoparticles. MAGMA (in press).

42. Zhang J, Zhu J, Bu X, Cushion M, Kinane TB, Avraham H et al. Cdc42 and RhoB activation are required for mannose receptor-mediated phagocytosis by human alveolar macrophages. Mol Biol Cell 2005; 16: 824-834.

43. Horak D, Babic M, Jendelova P, Herynek V, Trchova M, Pientka Z et al. D-Mannosemodified iron oxide nanoparticles for stem cell labeling. Bioconjug Chem (in press).

44. Allen M, Bulte JW, Liepold L, Basu G, Zywicke HA, Frank JA et al. Paramagnetic viral nanoparticles as potential high-relaxivity magnetic resonance contrast agents. Magn Reson Med 2005; 54: 807-812.

45. Bulte JW, Zhang SC, van Gelderen P, Herynek V, Jordan EK, Duncan ID et al. Neurotransplantation of magnetically labeled oligodendrocyte progenitors: magnetic resonance tracking of cell migration and myelination. Proc Natl Acad Sci USA 1999; 96 15256-15261.

46. Walczak P, Kedziorek DA, Gilad AA, Lin S, Bulte JW. Instant MR labeling of stem cells using magnetoelectroporation. Magn Reson Med 2005; 54: 769-774.

47. Brazelton TR, Rossi FM, Keshet GI, Blau HM. From marrow to brain: expression of neuronal phenotypes in adult mice. Science 2000; 290: 1775-1779.

48. Kopen GC, Prockop DJ, Phinney DG. Marrow stromal cells migrate throughout forebrain and cerebellum, and they differentiate into astrocytes after injection into neonatal mouse brains. Proc Natl Acad Sci USA 1999; 96: 10711-10716.

49. Honma T, Honmou O, lihoshi S, Harada K, Houkin K, Hamada H et al. Intravenous infusion of immortalized human mesenchymal stem cells protects against injury in a cerebral ischemia model in adult rat. Exp Neurol 2006; 199: 56-66.

50. Nomura T, Honmou O, Harada K, Houkin K, Hamada H, Kocsis JD. I.V. infusion of brainderived neurotrophic factor gene-modified human mesenchymal stem cells protects against injury in a cerebral ischemia model in adult rat. Neuroscience 2005; 136: 161-169.

51. Liu H, Honmou O, Harada K, Nakamura K, Houkin K, Hamada H et al. Neuroprotection by PIGF gene-modified human mesenchymal stem cells after cerebral ischaemia. Brain 2006 129 (Part 10): 2734-2745.

52. Horita Y, Honmou O, Harada K, Houkin K, Hamada H, Kocsis JD. Intravenous administration of glial cell line-derived neurotrophic factor gene-modified human mesenchymal stem cells protects against injury in a cerebral ischemia model in the adult rat. J Neurosci Res 2006; 84: 1495-1504.

53. Shyu WC, Chen CP, Lin SZ, Lee YJ, Li H. Efficient tracking of non-iron-labeled mesenchymal stem cells with serial MRI in chronic stroke rats. Stroke 2006; 38: 367-374.

54. Hofstetter CP, Schwarz EJ, Hess D, Widenfalk J, El Manira A, Prockop JD et al. Marrow stromal cells form guiding strands in the injured spinal cord and promote recovery. Proc Natl Acad Sci USA 2002; 96: 2199-2204.

55. Sykova $E$, Jendelova $P$. Magnetic resonance tracking of implanted adult and embryonic stem cells in injured brain and spinal cord. Ann N Y Acad Sci 2005; 1049: 146-160.

56. Sykova $E$, Jendelova $P$, Urdzikova L, Lesny $P$, Hejcl A. Bone marrow stem cells and polymer hydrogels-two strategies for spinal cord injury repair. Cell Mol Neurobiol 2006; 26: 1111-1127.

57. Sykova E, Homola A, Mazanec R, Lachman H, Langkramer Konradova S, Kobylka P et al. Autologous bone marrow transplantation in patients with subacute and chronic spinal cord injury. Cell Transplant 2006; 15: 675-687.

58. Park HC, Shim YS, Ha Y, Yoon SH, Park SR, Choi BH et al. Treatment of complete spinal cord injury patients by autologous bone marrow cell transplantation and administration of granulocyte-macrophage colony stimulating factor. Tissue Eng 2005; 11: 913-922.

59. Moviglia GA, Fernandez Vina R, Brizuela JA, Saslavsky J, Vrsalovic F, Varela G et al. Combined protocol of cell therapy for chronic spinal cord injury. Report on the electrical and functional recovery of two patients. Cytotherapy 2006; 8: 202-209

60. Mazzini L, Mareschi K, Ferrero I, Vassallo E, Oliveri G, Boccaletti R et al. Autologous mesenchymal stem cells: clinical applications in amyotrophic lateral sclerosis. Neurol Res 2006; 28: 523-526.

61. Sykova E, Jendelova P. In vivo tracking of stem cells in brain and spinal cord injury. Prog Brain Res (in press). 